\title{
Developing a Population Health Framework for Studying Problem Gambling
}

\author{
Tracie O. Afifi \\ University of Manitoba \\ Brian J. Cox \\ University of Manitoba \\ Patricia J. Martens \\ University of Manitoba and Manitoba Centre for Health Policy \\ Jitender Sareen \\ University of Manitoba \\ Murray W. Enns \\ University of Manitoba
}

\begin{abstract}
Research has shown that the expansion of gambling is an important public health concern and a public health approach should be applied to study problem gambling (Canadian Public Health Association, 2000; Korn, 2000; Korn \& Shaffer, 1999). However, such an approach is underutilized. Therefore, a conceptual framework was developed to study problem gambling (or pathological gambling) based on Evans and Stoddart's (1990) popular population health model. This framework can be used to identify psychosocial/social, genetic, and environmental correlates of problem gambling and important relationships between problem gambling and health and functioning, mental and physical health conditions, and help-seeking behaviours.
\end{abstract}

Keywords: gambling, problem gambling, pathological gambling, population health, public health

Tracie O. Afifi, Department of Community Health Sciences, Department of Psychiatry, and Department of Family Social Sciences, University of Manitoba, Winnipeg; Brian J. Cox, Department of Psychiatry, Department of Community Health Sciences, and Department of Psychology, University of Manitoba, Winnipeg; Patricia J. Martens, Department of Community Health Sciences, University of Manitoba, and Manitoba Centre for Health Policy, Winnipeg; Jitender Sareen, Department of Psychiatry, Department of Community Health Sciences, and Department of Psychology, University of Manitoba, Winnipeg; Murray W. Enns, Department of Psychiatry and Department of Community Health Sciences, University of Manitoba, Winnipeg.

The authors wish to acknowledge the funding and support received from the Social Sciences and Humanities Research Council of Canada - Canada Graduate Scholarship (Afifi), Canada Research Chair (Cox), Canadian Institutes of Health Research (CIHR/ PHAC) Applied Public Health Chair (Martens), and CIHR New Investigator Award (\#152348, Sareen).

Correspondence concerning this article should be addressed to Tracie O. Afifi, S113 Medical Services Bldg., 750 Bannatyne Avenue, Winnipeg MB R3E 0W3. Email: T_Afifi@umanitoba.ca 
The gambling industry has experienced significant worldwide growth over the past two decades. Researchers (Korn, 2000; Korn \& Shaffer, 1999) and the Canadian Public Health Association (2000) have recognized the increased availability of gambling as an important public health concern. Specifically, it is feared that with the growth of gambling opportunities comes increased gambling behaviour and gamblingrelated problems for the individual, family, and society. Problem gambling refers to gambling behaviour that has a negative impact on the gambler, others in his or her social network, or the community (Ferris \& Wynne, 2001). Over a decade ago, Korn and Shaffer (1999) suggested that a public health approach should be applied to understand problem gambling.

A population health model could provide clearer understanding of gambling and gambling-related problems in the general population. To date, a large proportion of problem-gambling research has used a medical perspective that has focused on diagnosing and treating individuals who meet Diagnostic and Statistical Manual of Mental Disorders (DSM) criteria for diagnosing pathological gambling (Castellani, 2000). Psychology models of behaviour, cognition, and addiction have also been applied to understand the pathways to gambling problems (Aasved, 2002). Although problem gambling is considered a public health problem and a population health approach is encouraged in the literature, this model is underutilized as a conceptual framework in research. A population health model could provide an informative conceptual framework for understanding problem gambling that moves beyond diagnosing and treating the most severe pathological gamblers and attempts to understand gambling and gambling-related problems in the general population. Problem gambling is a complex public health issue. To advance research in this area it is necessary to move the focus from diagnostic criteria toward a model that can consider the social and psychosocial environment, physical environment, genetic endowment, individual behaviour that contributes to the problem, health, and mechanisms that facilitate perceiving a need for help and help-seeking before individuals reach crisis. To accommodate these many domains, we chose the Evans and Stoddart (1990) population health model as the basis for developing a population health framework for studying problem gambling. This model is more comprehensive compared to a medical/disease perspective and goes beyond psychology and addiction models, which are relevant and informative but too narrowly focused on cognition and behaviour to accommodate a population health perspective.

The proposed population health model provides flexibility to include variables within these important domains and guidance for how to organize these variables in statistical modelling. This population health model could provide a more comprehensive, yet manageable examination of problem gambling that includes many population health domains. Therefore, the purpose of the present discussion is to use past research to develop and support a population health model that identifies correlates of problem gambling as well as important relationships between problem gambling and health and functioning, mental and physical health conditions, and help-seeking behaviours.

\section{A Population Health Model Developed by Evans and Stoddart (1990)}

Evans and Stoddart (1990) developed a well-known population health model, which is presented in Figure 1. The model includes genetic endowment, physical environment, social environment, individual response (behavioural and biological), health and functioning, disease, health care, prosperity, and wellbeing. Genetic endowment is the genetic inheritance and biological make-up of an individual. Physical 
environments include important aspects of one's physical surroundings such as exposure to specific elements. Social environments comprise socioeconomic factors, stress, social support, coping, and any other aspects that characterize social surroundings. All three - genetics, physical, and social environments - contribute to an individual's behavioural and biological responses, which in turn influence the individual's perception of health and functioning and whether the individual resists disease. When individuals perceive a need for medical care because of being hurt or sick, they may present themselves to the health care system where care will be provided. Prosperity is also in the model, which indicates that economic trade-offs may have an impact on well-being. The main outcome in the model is the sense of life satisfaction or well-being.

Figure 1

The Evans and Stoddart (1990) Population Health Model

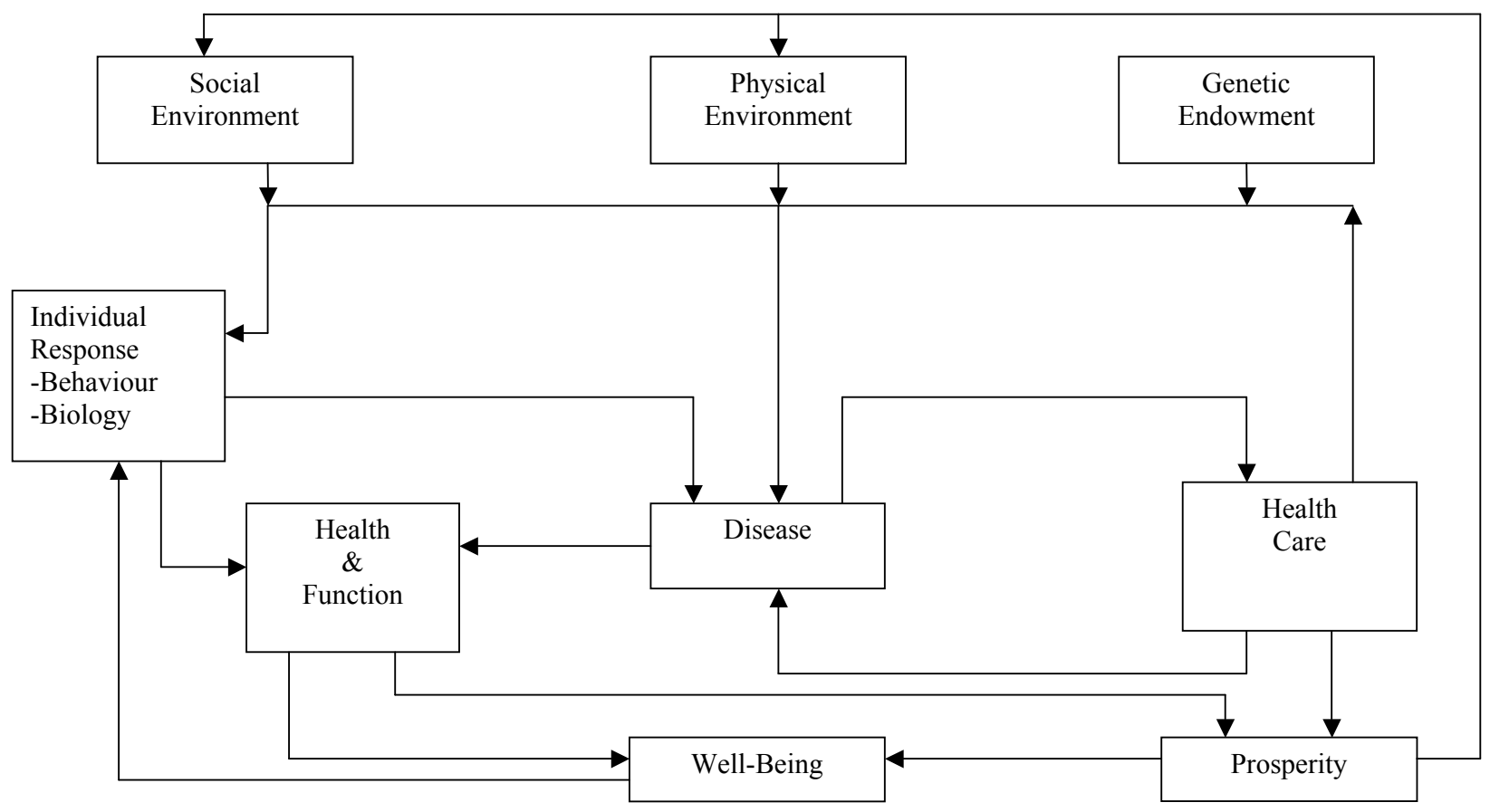

Source. Reprinted with permission from "Producing Health, Consuming Health Care," by R.G. Evans \& G.L. Stoddart, 1990, Social Science and Medicine, 31, pp. 1347-1363. Copyright 1990 by Elsevier.

Evans and Stoddart described the model as a comprehensive and flexible framework through which correlates of health can be examined (Evans \& Stoddart, 1990, 1994). In 2003, Evans and Stoddart reflected on their population health model and concluded that, although knowledge has advanced since the model was first created, it is still relevant and not in need of change. However, they indicated that new information should be incorporated into the model. One example is the influence of the social environment and individual 
psychology on health status. Therefore, when adapting Evans and Stoddart's model for studying problem gambling, we expanded the social environment to include psychosocial factors that may also have an impact on health. Table 1 provides a conceptual overview of one way the population health model can be applied to organize important variables and to study problem gambling in the general population.

Table 1

Conceptual Overview for Studying Problem Gambling in the General Population

Population health model domains $\quad$ Variables

(Application to gambling)

Social environment (social/psychosocial environment)

Physical environment (exposure to gambling)

Genetic endowment (family history of problem gambling)

Individual behaviour (gambling behaviour)

Health and functioning

Disease (health conditions)

Health care (help-seeking)
Age

Income

Education

Marital status

Social support

Stress

Coping

Concentration of VLTs per 1,000 population Presence permanent casino

Venue atmosphere

Gambling marketing and casino promotion

Family history of problem gambling Gender

Frequency and type of gambling Gambling-related problems

Perceived general health

Psychological well-being

Distress

Suicidal ideation

Suicide attempts

Comorbid mental health disorders

Chronic physical health conditions

Perceived need for help

Help-seeking 


\section{DEVELOPING A CONCEPTUAL FRAMEWORK FOR STUDYING PROBLEM GAMBLING}

\section{An Overview}

Genetic endowment (gender and familial gambling history), physical environment (availability, atmosphere, and marketing), and social/psychosocial environment (sociodemographic factors, social support, stress, and coping) function together to influence the occurrence and degree of gambling behaviour. Once gambling occurs, it may be only a means of recreation and gambling activities may not become problematic. However, if gambling problems occur and continue to progress, it can have a negative impact on functioning, physical and mental health, and may lead to perceiving a need for help and help-seeking.

Figure 2 presents a detailed conceptual framework, adapted from Evans and Stoddart (1990, 2003), for understanding problem gambling. The arrows in the diagram indicate single directional and bidirectional relationships. More specifically, genetic endowment, physical environment, and social/psychosocial environment all contribute to gambling behaviour and problem gambling (single direction arrows). The relationships between problem gambling and health and functioning, health conditions, and help-seeking could theoretically

Figure 2

\section{A Conceptual Framework for Understanding Problem Gambling}

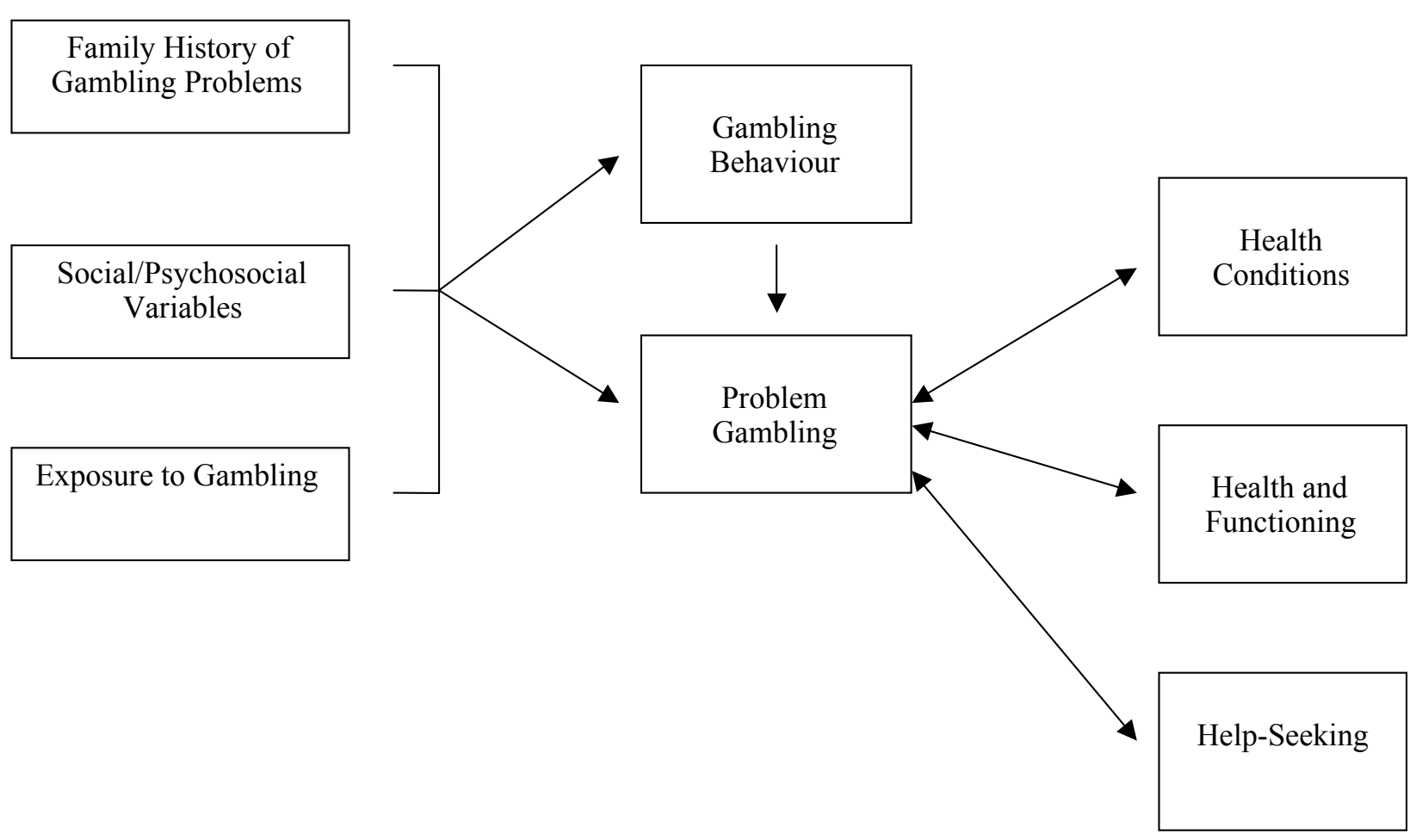


be bidirectional. Importantly, Figure 2 provides an example of how the Evans and Stoddart model can be applied to study problem gambling. The model is customized to include population health domains that are important and specific to the issue of problem gambling. Figure 2 allows researchers to organize variables and specify relationships between variables that are important to study in future research to further our understanding of problem gambling.

\section{Genetic Endowment}

Genetic endowment plays an influential role in the likelihood of experiencing mental health disorders and may contribute to problem-gambling behaviour. However, it is not clear if genetic predisposition exists for problem gambling (Walters, 2001). To illustrate, a meta-analysis of all genetic and gambling studies conducted between 1970 and $2000(n=19)$ indicated that genetic effects may be relatively weak, although not trivial, and that factors other than genetics are probably more important for understanding problem gambling (Walters, 2001).

A lack of robust support for genetic predisposition may relate to the changing physical environment and social attitudes toward gambling. Current gamblers may be unlikely to demonstrate a family history of (problem) gambling because of a historically low prevalence of gambling. This does not disprove a genetic association. As gambling increases in the population for any reason, opportunities to uncover genetic influences will increase. Nonetheless, support for a genetic influence on gambling does exist. Grant and Kim (2002) in a clinical sample of women problem gamblers found elevated levels of problem gambling among their fathers $(26.9 \%)$, mothers $(25.6 \%)$, siblings $(28.2 \%)$, and their own children $(6.4 \%)$. Another study found problem gambling was significantly more likely among first degree relatives of problem gamblers than in first degree relatives of the study control group (Black, Monahan, Temkit, \& Shaw, 2006). A family history of gambling problems was also commonly reported among women from a convenience sample from Ontario, Canada (Boughton \& Falenchuk, 2007). A longitudinal study of male twins found genetic factors contributed to $49 \%$ of the risk for at least one baseline gambling symptom, but there was no evidence for unique genetic contributions at the 10-year follow-up (Xian et al., 2007). Most recently, a twin study of men and women found the variance in disordered gambling was explained through genetic (49\%) and non-shared environmental (51\%) influences; shared environment did account for the variance in disordered gambling in these models (Slutske, Zhu, Meier, \& Martin, 2010).

Finally, it is important to mention the concepts of sex and gender when considering genetic endowment and problem gambling. Gender (men and women) is a social construct, whereas sex (male and female) is a biological construct (Krieger, 2003). The experience of problem gambling is not the same for men and women. Women, relative to men, start gambling at an older age, but progress toward gambling problems at a much faster pace (Grant \& Kim, 2002; Ibanez, Blanco, Moreryra, \& Saiz-Ruiz, 2003; Ladd \& Petry, 2002; Tavares et al., 2003; Tavares, Zilberman, Beites, \& Gentil, 2001). Therefore, women entering treatment may have been gambling only for a few years, while it might be common for men in treatment to indicate gambling for much longer (Rosenthal, 1992). Research investigating the progression of gambling problems among treatment seekers confirms that gender is an important variable that accounts for a large proportion of gambling problem progression, but may account for only a small proportion of unique variance when other psychosocial factors are considered (Nelson, LaPlante, LaBrie, \& Shaffer, 2006). The experience of problem 
gambling appears to be different for men and women, which is likely more a reflection of the sociocultural and psychosocial factors than the biological construct of being male or female and points to the need to study problem gambling separately among men and women when possible.

\section{Physical Environment}

Research indicates that the prevalence of problem gambling has risen since the widespread legalization and increased availability of gambling (Emerson \& Laundergan, 1996; Ladouceur, Jacques, Ferland, \& Giroux, 1999; Shaffer \& Hall, 2001; Shaffer, Hall, \& Vander Bilt, 1999). A study of undergraduate students from the United States indicated that students perceived gambling to be more available and less risky than buying marijuana or alcohol (Wickwire et al., 2007). The increase of casinos and Video Lottery Terminals (VLTs, also known as electronic gambling machines or slots) in the physical environment has been likened to an "environmental toxin" that causes disease (Shaffer, LaBrie, \& LaPlante, 2004). Various associations with gambling appear to confirm this environmental effect. For example, the exposure to gambling as measured by high concentration of VLTs in the community and the presence of a permanent casino was associated with increased prevalence of gambling problems (Cox, Yu, Afifi, \& Ladouceur, 2005). As well, problem gambling was associated with living within 10 miles of a casino (Welte, Wieczorek, Barnes, Tidwell, \& Hoffman, 2004). Casino employees have also been shown to experience greater gambling problems than the general population (Shaffer, Vander Bilt, \& Hall, 1999). These findings may reflect a type of dose-response relationship that underscores the importance of gambling exposure in relation to gambling activity. The number of different types of gambling and variety of gambling options is another significant aspect of the physical environment. Some individuals may engage in more than one type of gambling; the degree of gambling involvement may have an impact on gambling-related problems.

When discussing exposure to gambling, it is important to reflect on the role of advertising and marketing. Promotional advertising is another salient environmental factor and may itself trigger gambling behaviour. Advertising can increase the visibility of gambling and possibly manipulate peoples' perception of gambling as harmless, exciting, and socially acceptable. A qualitative study of women with gambling problems from Australia illustrated the importance of the physical environment on gambling behaviour (Brown \& Conventry, 1997). Women in the study indicated that promotional gambling advertising was influential, environments were attractive, and locations accessible. These findings emphasize the importance of physical environment and the specific factors it accommodates: availability, atmosphere, and marketing.

\section{Social/Psychosocial Environment}

Sociodemographic factors. Inconsistencies in the literature with regard to sociodemographic factors and problem gambling may be due to data discrepancy when using clinical, convenience, and representative community samples. In a nationally representative Canadian study, increased odds of problem gambling among women were associated with being middle aged, having middle to low income, having high school diploma or less, and being never married; among men, being separated, widowed, or divorced increased the odds of problem gambling while being aged 70 or greater decreased the odds (Afifi, Cox, Martens, Sareen, $\&$ Enns, 2010a). When directly comparing men and women problem gamblers in this study, gender-related differences were found for age and income. 
An interesting relationship exists between income and problem gambling. MacDonald, McMullan, and Perrier (2004) found that individuals earning $\$ 20,000$ or less per year spent a mean of $2.0 \%$ of their income on gambling compared to a mean of $1.0 \%$ of earned income spent among those making $\$ 20,000$ to $\$ 39,999$ and a mean of $0.4 \%$ of earned income spent among those making $\$ 80,000$ or more. The higher earners may gamble with larger amounts of money, but it may be people in the middle to low income brackets who are at the greatest risk for developing gambling problems.

Supportiveness and social relationships. Having supportive social relationships is associated with better health outcomes (Chomik, 2001). Likewise, problem gambling has been found to be more prevalent among individuals with poor social support networks (Zaranek \& Chapleski, 2005). Some argue, however, that a potential benefit of gambling is that it can provide a sense of social connectedness (Korn \& Shaffer, 1999; Shaffer \& Korn, 2002; Vander Bilt, Dodge, Pandav, Shaffer, \& Ganguli, 2004). In a nationally representative Canadian sample, higher levels of social support decreased the odds of problem gambling among men, but this relationship was not significant among women (Afifi et al., 2010a). However, when directly comparing men problem gamblers to women problem gamblers, greater social support increased the odds of problem gambling among women, suggesting that gambling may be a social event in women's lives and play a different role among men. A study of older adults indicated that machine gambling provided an opportunity to make friends and socialize (Southwell, Boreham, \& Laffan, 2008). Gambling may provide a sense of belonging, but gambling is often an isolated activity involving little social interaction or connectedness. Additionally, clinical and convenience samples have indicated that loneliness was a reason for gambling (Brown \& Conventry, 1997; Grant \& Kim, 2002). Further research to clarify the social or isolating nature of gambling and the relationship between social support and gambling problems is necessary.

Stress and coping. Evans and Stoddart (1990) mention the potentially harmful impact of stress and the protective role of effective coping in determining health. Not surprisingly, problem gamblers have been found to report higher levels of life stress and stress-related illness (Christensen, Patsdaughter, \& Babington, 2001; Collins \& Lapsley, 2003; Volberg, 2002). Although gambling can provide a perceived relief from stress (Boughton \& Falenchuk, 2007), it has been found that gambling problems are associated with poor coping skills (Afifi et al., 2010a; Getty, Watson, \& Frisch, 2000; Scannell, Quirk, Smith, Maddern, \& Dickerson, 2000; Sharpe \& Tarrier, 1993; Shepherd \& Dickerson, 2001). As well, the inability to cope with stressful situations has also been implicated in relapses of problem gambling behaviour (Ledgerwood \& Petry, 2006). Individuals may gamble as a means of coping with painful events in their lives (Smith \& Wynne, 2004) or negative mood, which over time may intensify leading to greater levels of gambling (Getty et al., 2000). A qualitative study of men and women from the United Kingdom indicated that many respondents reported gambling as a means of escape-based coping, which facilitated the continuation of problem gambling (Wood \& Griffiths, 2007).

\section{Individual Response}

According to the population health model, genes, physical environment, and social environment function together and influence the response of the individual (Evans \& Stoddart, 1990). The behavioural and biological response of an individual has an impact on health outcomes including disease, and health and 
functioning. This process can be specifically applied to gambling. With regard to gambling, the individual behavioural response is the type and frequency of gambling and amount of money spent on gambling. Researchers investigating at-risk levels of gambling activity have suggested that gambling activities should be limited to no more than two to three times per month and spending no more than $\$ 501$ to $\$ 1,000$ Canadian dollars per year or approximately 1\% of gross household annual income (Currie et al., 2006; Currie et al., 2008). Research has also indicated that greater frequency of gambling on VLTs outside casinos, VLTs inside casinos, other casino games, bingo, lottery tickets, and instant win tickets corresponds with increasing odds of problem gambling (Afifi, Cox, Martens, Sareen, \& Enns, 2010c). The development of gambling problems and gambling-related stress may also have an impact on an individual's biological response. Excessive gambling activity may, in turn, have a broad impact on health and functioning and presence of disease.

\section{Health and Functioning}

General health and functioning. Research has indicated that problem gamblers compared to nonproblem gamblers are more likely to perceive their general health as fair or poor or indicate lower healthrelated quality of life (Afifi, Cox, Martens, Sareen, \& Enns, 2010b; Erickson, Molina, Ladd, Pietrzak, \& Petry, 2005; Marshall \& Wynne, 2003, 2004; Mason \& Arnold, 2007; Pietrzak, Molina, Ladd, Kerins, \& Petry, 2005; Scherrer et al., 2005). Many studies on gambling and general health are not comparable because of differences in samples and measures. However, a study using a sample of urban adult primary care patients found that measures of overall self-reported physical and mental health assessed using the Short Form 12 (SF-12, a 12-item scale measuring self-reported mental and physical health) decreased as the gambling behaviour worsened from non-gamblers, recreational gamblers, problem gamblers, to pathological gamblers (Morasco, vom Eigen, \& Petry, 2006). Similarly, a representative New Zealand sample indicated that problem gamblers compared to non-problem gamblers were more likely to have poor self-reported mental and physical health according to the SF-36, a 36-item scale measuring self-reported mental and physical health (Mason \& Arnold, 2007).

Suicidal ideation and attempts. Challenges arise when trying to determine if problem gambling is the cause of completed suicides, and the degree of this problem in society (Shaffer \& Korn, 2002). An investigation found that the introduction of new casinos in specified communities did not correspond with an increase in completed suicides (Nichols, Stitt, \& Giacopassi, 2004). Non-significant findings may indicate a true "non-effect," or may be due to the short time frame of the study, small sample size (type II error), or inability to determine if death was the result of a suicide. Although it is difficult to determine if suicide completion is a result of gambling problems, copious research has indicated that problem gambling is associated with suicidal ideation and attempts (Afifi et al., 2010b; Beaudion \& Cox, 1999; Bland, Newman, Orn, \& Stebelsky, 1993; Boughton \& Falenchuk, 2007; Cunningham Williams et al., 2005; Doiron \& Nicki, 2001; Gill, Dal Grande, \& Taylor, 2006; Ibanez et al., 2003; Ledgerwood, Steinberg, Wu, \& Potenza, 2005; Martins, Tavares, Silva-Lobo, Galetti, \& Gentil, 2004; Newman \& Thompson, 2003, 2007; Potenza et al., 2001). For example, a study using a national sample from Canada found that the most severe level of problem gambling was associated with suicide attempts (odds ratio 3.43; $95 \% \mathrm{CI}=1.37$ to 8.60 ) after adjusting for sociodemographic and mental health variables (Newman \& Thompson, 2007). 


\section{Health Conditions}

Physical health conditions. Volberg (2002) indicates that public health risks of problem gambling include stress-related illnesses such as hypertension and heart disease. However, limited research has been conducted on physical health conditions and problem gambling. Studies using older adult samples have found relationships between problem gambling and having a chronic medical problem (Burge, Pietrzak, Molina, \& Petry, 2004; Desai, Desai, \& Potenza, 2007; Pietrzak et al., 2005). Reseach examining a clinical sample of problem gamblers from Quebec determined that approximately two thirds of respondents reported a medical problem such as insomnia, headaches, or stomach aches at least once a week due to gambling (Ladouceur, Boisvert, Pepin, Loranger, \& Sylvain, 1994). In a random community sample from Prince Edward Island, problem gamblers were more likely than non-problem gamblers to report being diagnosed with a stressrelated illness (Doiron \& Nicki, 2001).

Using a representative sample from the United States, significant relationships between lifetime gambling problems and past year self-reported physician-diagnosed hypertension, tachycardia, angina, cirrhosis, other liver disease, and arthritis were found (Morasco et al., 2006). Although this study provided evidence for a relationship between gambling problems and physical health conditions, it was limited since the measurement time frame of gambling problems (lifetime) and physical health conditions (past year) were different, which may reduce the substantive significance of the findings. Also, men and women were not studied separately, which is important since the prevalence of some health conditions differs among men and women and a combined sample eliminates the possibility of understanding such relationships. In another representative sample, problem gambling was associated with increased odds of only 3 of the 17 health conditions among Canadian women; authors concluded that the relationship between problem gambling and physical health conditions was not supported (Afifi et al., 2010b). It is not yet clear whether problem gambling leads to health conditions or if health conditions precede problem gambling. If a relationship does exist between problem gambling and health conditions, the directionally of this relationship is likely bidirectional. Further research on problem gambling and physical health using longitudinal, prospective data is necessary.

Mental health disorders. An early review article found that pathological gambling was often comorbid with substance use disorders and likely comorbid with antisocial personality and mood disorders (Crockford \& el-Guebaly, 1998). Clinical samples have found that problem gambling is often comorbid with mood, anxiety, and substance use disorders (Dannon et al., 2004; Hodgins, Peden, \& Cassidy, 2005; MacCallum \& Blaszcynski, 2002; Specker, Carlson, Edmonson, Johnson, \& Marcotte, 1996). A recent study from the United States using nationally representative data found that among pathological gamblers, $73 \%$ had an alcohol use disorder, $38 \%$ had a drug use disorder, $60 \%$ had nicotine dependence, $50 \%$ had a mood disorder, $41 \%$ had an anxiety disorder, and 61\% had a personality disorder (Petry, Stinson, \& Grant, 2005). Other studies using nationally representative data from Canada found that individuals with bipolar I disorder were 2.3 times more likely to be problem gamblers than those without bipolar I disorder (McIntyre et al., 2007), and that those with a mood or anxiety disorder and those with substance dependence or harmful alcohol use were significantly more likely to be problem gamblers compared to those without a psychiatric diagnosis (el-Guebaly et al., 2006). In a representative sample of Canadian women, problem gambling was associated with increased odds of depression, mania, panic attacks, social phobia, agoraphobia, alcohol dependence, and mental health comorbidity (Afifi et al., 2010b). 
Internalizing disorders such as depression are more prevalent among women relative to men (Kessler, 2003; Kessler et al., 2003) and, therefore, it would seem that comorbidity of depression would be more likely among women problem gamblers compared to men problem gamblers. A study using a nationally representative sample from the United States found that women problem gamblers were more likely to experience lifetime mood and anxiety disorders than men problem gamblers (Blanco, Hasin, Petry, Stinson, \& Grant, 2006). Another study using the same data indicated that significantly stronger associations existed between past year mood and anxiety disorders and past year problem gambling in women compared to men (Desai \& Potenza, 2008). As well, research using clinical and community samples found that women problem gamblers are more likely to experience comorbid depression or mood disorders than men problem gamblers (Ibanez et al., 2001; Petry et al., 2005).

Mental health disorders may develop before, after, or concurrently with gambling problems. Little information is available regarding the temporal association between gambling and mental health disorders (Cunningham-Williams \& Cottler, 2001). One recent study attempted to understand the directionality of this relationship using age of onset data among a sample of recovering problem gamblers (Hodgins et al., 2005). Findings from the study indicated that depression was just as likely to occur before or after gambling problems suggesting that some individuals may use gambling as a poor coping mechanism to relieve dysphoric mood, while other individuals may become depressed because of their gambling problems. However, 74\% of individuals experienced alcohol abuse/dependence and $84 \%$ experienced drug abuse/dependence before gambling problems. Another study using age onset information from the National Comorbidity Survey Replication data indicated that DSM-IV pathological gambling often occurred after several DSM-IV mental disorders, including anxiety, mood, impulse-control, and substance use disorders (Kessler et al., 2008). These studies are the first to shed light on the temporal relationship between problem gambling and comorbid mental health disorders. However, well-designed longitudinal prospective studies using representative samples are still needed to further clarify this relationship.

\section{Health Care: Help-Seeking}

From a population health perspective, help-seeking for gambling problems should include help-seeking from services such as professional counselling, therapy, or rehabilitation services, telephone gambling help lines, and self-help groups. Identifying a problem or symptoms of distress is a necessary first step in the process of seeking help (Clarke, Abbott, DeSouza, \& Bellringer, 2007). When gambling becomes very problematic, an individual may perceive a need for help with gambling problems, emotions, mental health problems, physical health symptoms, financial crises, and other related tribulations. Problems with gambling may then initiate help-seeking behaviour. One study from Montreal, Canada, indicated that from 2000 to 2004 the number of psychiatric emergency services used by individuals with severe gambling problems increased by over 50\% (Chaput, Lebel, Labonte, Beaulieu, \& Paradis, 2007). In a representative study of Canadian women, problem gambling was associated with increased odds of help-seeking from a professional, a self-help group, and a telephone helpline (Afifi et al., 2010b). However, it is important to consider that individual, social, and structural factors may influence the recognition of a gambling problem and the

willingness to seek help. Gender, culture, and awareness of services may be examples of factors that hinder the identification of a gambling problem, perceived need for help, and help-seeking. Help-seeking for many 
individuals may not occur until their gambling behaviour has created a crisis and informal resources (e.g., friends and family) have been depleted (Clarke et al., 2007; Evans \& Delfabbro, 2005).

\section{OVERALL STRENGTHS AND LIMITATIONS OF THE MODEL}

A strength of Evans and Stoddart's model is that it is parsimonious, yet comprehensive enough to include many important health correlates. As such, the model recognizes that many factors contribute to overall health or well-being and that it is important to consider these factors together. The population health model represents a set of categories or domains useful for organizing data to conceptualize or test the relationships between health correlates and health outcomes. Evans and Stoddart's population health model has been applied or adapted to understand the health determinants of many health topics including chronic disease (Barr et al., 2003) and urban living (Galea, Freudenberg, \& Vlahov, 2005). The main limitations of the model are that directionality of some paths could be argued, making the model more useful as a conceptual framework of categories to organize data than to compare and relate data (Evans \& Stoddart, 1990, 2003). Another limitation of the population health model is that it is often not possible to operationally define and empirically test all the concepts described in the model. Additionally, Evans and Stoddart's model has received criticism for underestimating the impact of health care on health and well-being, and for the lack of social theory or capacity to properly integrate the social context (Poland, Coburn, Robertson, \& Eakin, 1998). Although these criticisms are warranted, the utility of the population health model is for organizing data and highlighting important relationships. This model is flexible and can be expanded to include the social context within the social domain when necessary. The model is also easily applied to develop statistical models for furthering our understanding of problem gambling. However, we have attempted to address some of these shortfalls of Evans and Stoddart's model through the expansion of the social environment to also include psychosocial determinants.

\section{CONCLUSION}

The application of the Evans and Stoddart (1990) population health model provides a flexible and comprehensive way to conceptualize and study problem gambling. The conceptual framework can be applied to various research questions and specific populations, such as women and adolescents. To date, a small but growing literature has used a population health perspective for studying problem gambling. Using the proposed population health framework to study problem gambling may help fill in current gaps of knowledge on problem gambling in the general population such as the possible relationships between gambling and genetics, social support, and physical health problems. Additional studies using a population health perspective would be useful to clarify our understanding of problem gambling, specifically in areas where data are insufficient or inconsistent. Developing frameworks to guide research is needed and has the potential to advance the current problem gambling literature. 


\section{RÉSUMÉ}

La recherche a montré que l'augmentation du nombre de joueurs compulsifs est un important problème de santé publique, et qu'il faut donc utiliser une approche de santé publique pour étudier la question (Association canadienne de santé publique, 2000 ; Korn, 2000 ; Korn et Shaffer, 1999). Pourtant, cela se fait peu. C'est pourquoi nous avons conçu un cadre conceptuel pour étudier le jeu compulsif (ou le jeu pathologique), à partir du modèle de santé de la population d'Evans et Stoddart (1990). Ce cadre permet d'établir des corrélats de nature génétique et liés aux milieux social et physique, et des liens importants entre le jeu compulsif et la santé et le fonctionnement des personnes, leur santé mentale et physique, et leurs façons de chercher ou non de l'aide.

Mots clés : jeu, jeu compulsif, jeu pathologique, santé de la population, santé publique

\section{REFERENCES}

Aasved, M. (2002). The psychodynamics and psychology of gambling (Vol. 1). Springfield, IL: Charles C. Thomas Publisher.

Afifi, T.O., Cox, B.J., Martens, P.J., Sareen, J., \& Enns, M.W. (2010a). Demographic and social variables associated with problem gambling among men and women in Canada. Psychiatry Research, 178, 395-400.

Afifi, T.O., Cox, B.J., Martens, P.J., Sareen, J., \& Enns, M.W. (2010b). The relationship between problem gambling and mental and physical health correlates among a nationally representative sample of Canadian women. Canadian Journal of Public Health, 101, 171-175.

Afifi, T.O., Cox, B.J., Martens, P.J., Sareen, J., \& Enns, M.W. (2010c). The relationship between types and frequency of gambling activities and problem gambling among women in Canada. Canadian Journal of Psychiatry, 55, 21-28.

Barr, V.J., Robinson, S., Marin-Link, B., Underhill, L., Dotts, A., Ravensdale, D., \& Salivaras, S. (2003). The expanded chronic care model: An integration of concepts and strategies from popualtion health promotion and the chronic care model. Hospital Quarterly, 7(1), 73-82.

Beaudion, C.M., \& Cox, B.J. (1999). Characteristics of problem gambling in a Canadian context: A preliminary study using a DSM-IV-based questionnaire. Canadian Journal of Psychiatry, 44(5), 483-487.

Black, D.W., Monahan, P.O., Temkit, M., \& Shaw, M. (2006). A family study of pathological gambling. Psychiatry Research, 141, 295-303.

Blanco, C., Hasin, D.S., Petry, N., Stinson, F.S., \& Grant, B.F. (2006). Sex differences in subclinical and DSM-IV pathological gambling: Results from the National Epidemiologic Survey on Alcohol and Related Conditions. Psychological Medicine, 36, 943-953.

Bland, R.C., Newman, S.C., Orn, H., \& Stebelsky, G. (1993). Epidemiology of pathological gambling in Edmonton. Canadian Journal of Psychiatry, 38, 108-112.

Boughton, R., \& Falenchuk, O. (2007). Vulnerability and comorbidity factors of female problem gambling. Journal of Gambling Studies, 23, 323-334.

Brown, S., \& Conventry, L. (1997). Queen of hearts: The needs of women with gambling problems. Victoria, Australia: Financial and Consumer Rights Council.

Burge, A.N., Pietrzak, R.H., Molina, C.A., \& Petry, N.M. (2004). Age of gambling initiation and severity of gambling and health problems among older adult problem gamblers. Psychiatric Services, 55, 1437-1439.

Canadian Public Health Association. (2000). Gambling expansion in Canada: An emerging public health issue. Position paper.

Castellani, B. (2000). Pathological gambling: The making of a medical problem. Albany, NY: State University of New York Press.

Chaput, Y., Lebel, M.-J., Labonte, E., Beaulieu, L., \& Paradis, M. (2007). Pathological gambling and the psychiatric emergency service. Canadian Journal of Psychiatry, 52, 535-538.

Chomik, T.A. (2001). The population health template: Key elements and actions that define a population health approach. Report prepared for Health Canada. 
Christensen, M.H., Patsdaughter, C.A., \& Babington, L.M. (2001). Health care providers' experiences with problem gambling. Journal of Gambling Studies, 17, 71-79.

Clarke, D., Abbott, M., DeSouza, R., \& Bellringer, M. (2007). An overview of help seeking by problem gamblers and their families including barriers to and relevance of services. International Journal of Mental Health Addiction, 5, 292-306.

Collins, D., \& Lapsley, H. (2003). The social costs and benefits of gambling: An introduction to the economic issues. Journal of Gambling Studies, 19, 123-148.

Cox, B.J., Yu, N., Afifi, T.O., \& Ladouceur, R. (2005). A national survey of gambling problems in Canada. Canadian Journal of Psychiatry, 50, 213-217.

Crockford, D.N., \& el-Guebaly, N. (1998). Psychiatric comorbidity in pathological gambling: A critical review. Canadian Journal of Psychiatry, 43, 43-50.

Cunningham-Williams, R.M., \& Cottler, L.B. (2001). The epidemiology of pathological gambling. Seminars in Clinical Neuropsychiatry, 6, 155-166.

Cunningham-Williams, R.M., Grucza, R.A., Cottler, L.B., Womack, S.B., Books, S.J., Przybeck, T.R., ... Cloninger, R.C. (2005). Prevalence and predictors of pathological gambling: Results from the St. Louis personality, health and lifestyle (SLPHL) study. Journal of Psychiatric Research, 39(4), 377-390.

Currie, S.R., Hodgins, D.C., Wang, J., el-Guebaly, N., Wynne, H., \& Chen, S. (2006). Risk of harm among gamblers in the general population as a function of level of participation in gambling activities. Addiction, 101, 570-580.

Currie, S.R., Hodgins, D.C., Wang, J., el-Guebaly, N., Wynne, H., \& Miller, N.V. (2008). Replication of low-risk gambling limits using Canadian provincial gambling prevalence data. Journal of Gambling Studies, 24, 257-274.

Dannon, P.N., Lowengrub, K., Sasson, M., Shalgi, B., Tuson, L., Saphir, Y., \& Kotler, M. (2004). Comorbid psychiatric diagnoses in kleptomania and pathological gambling: A preliminary comparison study. European Psychiatry, 19(5), 299-302.

Desai, R.A., Desai, M.M., \& Potenza, M.N. (2007). Gambling, health, and age: Data from the National Epidemiologic Survey on Alcohol and Related Conditions. Psychology of Addictive Behaviors, 21, 431-440.

Desai, R.A., \& Potenza, M.N. (2008). Gender differences in the associations between past-year gambling problems and psychiatric disorders. Social Psychiatry and Psychiatric Epidemiology, 43, 173-183.

Doiron, J.P., \& Nicki, R.M. (2001). Epidemiology of problem gambling in Prince Edward Island: A Canadian microcosm? Canadian Journal of Psychiatry, 46, 413-417.

el-Guebaly, N., Patten, S.B., Currie, S., Williams, J.V.A., Beck, C.A., Maxwell, C.J., \& Wang, J.L. (2006). Epidemiology associations between gambling behavior, substance use and mood and anxiety disorders. Journal of Gambling Studies, 22(3), 275-287.

Emerson, M.O., \& Laundergan, J.C. (1996). Gambling and problem gambling among adult Minnesotans: Changes 1990 to 1994. Journal of Gambling Studies, 12, 291-304.

Erickson, L., Molina, C.A., Ladd, G.T., Pietrzak, R.H., \& Petry, N.M. (2005). Problem and pathological gambling are associated with poor mental and physical health in older adults. International Journal of Geriatric Psychiatry, 20, 754-759.

Evans, L., \& Delfabbro, P.H. (2005). Motivators for change and barriers to help-seeking in Australian problem gamblers. Journal of Gambling Studies, 21, 133-155.

Evans, R.G., \& Stoddart, G.L. (1990). Producing health, consuming health care. Social Sciences and Medicine, 31, 1347-1363.

Evans, R.G., \& Stoddart, G.L. (1994). Producing health, consuming health care. In R.G. Evans, M.L. Barer, \& T.R. Marmor (Eds.), Why are some people healthy and others are not? (pp. 27-64). New York, NY: Aldine De Gruyter.

Evans, R.G., \& Stoddart, G.L. (2003). Consuming research, producing policy? American Journal of Public Health, 93, 371-379.

Ferris, J., \& Wynne, H. (2001). The Canadian Problem Gambling Index: Final report. Submitted for the Canadian Centre on Substance Abuse.

Galea, S., Freudenberg, N., \& Vlahov, D. (2005). Cities and population health. Social Science \& Medicine, 60, 1017-1033.

Getty, H.A., Watson, J., \& Frisch, G.R. (2000). A comparison of depression and styles of coping in male and female GA members and controls. Journal of Gambling Studies, 16, 377-391. 
Gill, T., Dal Grande, E., \& Taylor, A.W. (2006). Factors associated with gamblers: A population-based cross-sectional study of south Australian adults. Journal of Gambling Studies, 22, 143-164.

Grant, J.E., \& Kim, S.W. (2002). Gender differences in pathological gamblers seeking medication treatment. Comprehensive Psychiatry, 43, 56-62.

Hodgins, D.C., Peden, N., \& Cassidy, E. (2005). The association between comorbidity and outcome in pathological gambling: A prospective follow-up of recent quitters. Journal of Gambling Studies, 21, 255-271.

Ibanez, A., Blanco, C., Donahue, E., Lesieur, H.R., Perez de Castro, I., Fernandez-Piqueras, J., \& Saiz-Ruiz, J. (2001). Psychiatric comorbidity in pathological gamblers seeking treatment. American Journal of Psychiatry, 158, 1733-1735.

Ibanez, A., Blanco, C., Moreryra, P., \& Saiz-Ruiz, J. (2003). Gender differences in pathological gambling. Journal of Clinical Psychiatry, 64, 295-301.

Kessler, R.C. (2003). Epidemiology of women and depression. Journal of Affective Disorders, 74, 5-13.

Kessler, R.C., Berglund, P., Demler, O., Jin, R., Koretz, D., Merikangas, K.R., .. Wang, P.S. (2003). The epidemiology of major depressive disorder. Journal of the American Medical Association, 289(23), 3095-3105.

Kessler, R.C., Hwang, I., LaBrie, R., Petukhova, M., Sampson, N.A., Winters, K.C., \& Shaffer, H.J. (2008). DSM-IV pathological gambling in the National Comorbidity Survey Replication. Psychological Medicine, 38(9), 1351-1360.

Korn, D.A. (2000). Expansion of gambling in Canada: Implications for health and social policy. Canadian Medical Association Journal, 163, 61-64.

Korn, D.A., \& Shaffer, H.J. (1999). Gambling and the health of the public: Adopting a public health perspective. Journal of Gambling Studies, 15, 289-365.

Krieger, N. (2003). Genders, sexes, and health: What are the connections - And why does it matter? International Journal of Epidemiology, 32, 652-657.

Ladd, G.T., \& Petry, N.M. (2002). Gender differences among pathological gamblers seeking treatment. Experimental and Clinical Psychopharmacology, 10, 302-309.

Ladouceur, R., Boisvert, J.-M., Pepin, M., Loranger, M., \& Sylvain, C. (1994). Social cost of pathological gambling. Journal of Gambling Studies, 10, 399-409.

Ladouceur, R., Jacques, C., Ferland, F., \& Giroux, I. (1999). Prevalence of problem gambling: A replication study 7 years later. Canadian Journal of Psychiatry, 44, 802-804.

Ledgerwood, D.M., \& Petry, N.M. (2006). What do we know about relapse in pathological gambling? Clinical Psychology Reviews, 26, 216-228.

Ledgerwood, D.M., Steinberg, M.A., Wu, R., \& Potenza, M.N. (2005). Self-reported gambling-related suicidality among gambling helpline callers. Psychology of Addictive Behaviors, 19, 175-183.

MacCallum, F., \& Blaszcynski, A. (2002). Pathological gambling and comorbid substance use. Australian and New Zealand Journal of Psychiatry, 36, 411-415.

MacDonald, M., McMullan, J.L., \& Perrier, D.C. (2004). Gambling households in Canada. Journal of Gambling Studies, 20, 187-236.

Marshall, K., \& Wynne, H. (2003). Fighting the odds. Perspectives, 4(12), 5-13.

Marshall, K., \& Wynne, H. (2004). Against the odds: A profile of at-risk and problem gamblers. Canadian Social Trends, 73, 25-29.

Martins, S.S., Tavares, H., Silva-Lobo, D.S., Galetti, A.M., \& Gentil, V. (2004). Pathological gambling, gender, and risk-taking behaviors. Addictive Behaviors, 29, 1231-1235.

Mason, K., \& Arnold, R. (2007). Problem gambling risk factors and associated behaviours and health status: Results from the 2002/03 New Zealand Health Survey. The New Zealand Medical Journal, 120, U2604-U2616.

McIntyre, R.S., McElroy, S.L., Konarski, J.Z., Soczynska, J.K., Wilkins, K., \& Kennedy, S.H. (2007). Problem gambling in bipolar disorder: Results from the Canadian Community Health Survey. Journal of Affective Disorders, 102, 27-34.

Morasco, B.J., Pietrzak, R.H., Blanco, C., Grant, B.F., Hasin, D., \& Petry, N.M. (2006). Health problems and medical utilization associated with gambling disorders: Results from the National Epidemiologic Survey on Alcohol and Related Conditions. Psychosomatic Medicine, 68, 976-984.

Morasco, B.J., vom Eigen, K.A., \& Petry, N.M. (2006). Severity of gambling is associated with physical and emotional health in urban primary care patients. General Hospital Psychiatry, 28, 94-100. 
Nelson, S.E., LaPlante, D.A., LaBrie, R.A., \& Shaffer, H.J. (2006). The proxy effect: Gender and gambling problem trajectories of Iowa gambling treatment program participants. Journal of Gambling Studies, 22, 221-240.

Newman, S.C., \& Thompson, A.H. (2003). A population-based study of the association between pathological gambling and attempted suicide. Suicide and Life Threatening Behavior, 33, 80-87.

Newman, S.C., \& Thompson, A.H. (2007). The association between pathological gambling and attempted suicide: Findings from a national survey in Canada. Canadian Journal of Psychiatry, 52, 605-612.

Nichols, M.W., Stitt, B.G., \& Giacopassi, D. (2004). Changes in suicide and divorce in new casino jurisdictions. Journal of Gambling Studies, 20, 391-404.

Petry, N.M., Stinson, F.S., \& Grant, B.F. (2005). Comorbidity of DSM-IV pathological gambling and other psychiatric disorders: Results from the National Epidemiologic Survey on Alcohol and Related Conditions. Journal of Clinical Psychiatry, 66, 564-574.

Pietrzak, R.H., Molina, C.A., Ladd, G.T., Kerins, G.J., \& Petry, N.M. (2005). Health and psychosocial correlates of disordered gambling in older adults. American Journal of Geriatric Psychiatry, 13, 510-519.

Poland, B., Coburn, D., Robertson, A., \& Eakin, J. (1998). Wealth, equity and health care: A critique of a "population health" perspective on the determinants of health. Social Science \& Medicine, 46, 785-798.

Potenza, M.N., Steinberg, M.A., McLaughlin, S.D., Wu, R., Rounsaville, B.J., \& O’Malley, S.S. (2001). Gender-related differences in the characteristics of problem gamblers using a gambling helpline. American Journal of Psychiatry, $158,1500-1505$.

Rosenthal, R.J. (1992). Pathological gambling. Psychiatric Annals, 22, 72-78.

Scannell, E.D., Quirk, M.M., Smith, K., Maddern, R., \& Dickerson, M. (2000). Females' coping styles and control over poker machine gambling. Journal of Gambling Studies, 16, 417-432.

Scherrer, J.F., Xian, H., Shah, K.R., Volberg, R., Slutske, W., \& Eisen, S.A. (2005). Effect of genes, environment, and lifetime co-occurring disorders on health-related quality of life in problem and pathological gamblers. Archives of General Psychiatry, 62, 677-683.

Shaffer, H.J., \& Hall, M.N. (2001). Updating and refining prevalence estimates of disordered gambling behaviour in the United States and Canada. Canadian Journal of Public Health, 92, 168-712.

Shaffer, H.J., Hall, M.N., \& Vander Bilt, J. (1999). Estimating the prevalence of disordered gambling behavior in the United States and Canada: A research synthesis. American Journal of Public Health, 89, 1369-1376.

Shaffer, H.J., \& Korn, D.A. (2002). Gambling and related mental disorders: A public health analysis. Annual Review of Public Health, 23, 171-212.

Shaffer, H.J., LaBrie, R.A., \& LaPlante, D.A. (2004). Laying the foundation for quantifying regional exposure to social phenomena: Considering the case of legalized gambling as a public health toxin. Psychology of Addictive Behaviors, 18, 40-48.

Shaffer, H.J., Vander Bilt, J., \& Hall, M.N. (1999). Gambling, drinking, smoking and other health risk activities among casino employees. American Journal of Industrial Medicine, 36, 365-378.

Sharpe, L., \& Tarrier, N. (1993). Towards a cognitive-behavioural theory of problem gambling. British Journal of Psychiatry, 162, 407-412.

Shepherd, L., \& Dickerson, M. (2001). Situational coping with loss and control over gambling in regular poker machine players. Australian Journal of Psychology, 53, 160-169.

Slutske, W.S., Zhu, G., Meier, M.H., \& Martin, N.G. (2010). Genetic and environmental influences on disordered gambling in men and women. Archives of General Psychiatry, 67, 624-630.

Smith, G.J., \& Wynne, H. (2004). VLT gambling in Alberta: A preliminary analysis. Unpublished manuscript, Alberta Gaming Research Institute.

Southwell, J., Boreham, P., \& Laffan, W. (2008). Problem gambling and the circumstances facing older people: A study of gaming machine players age 60+ in licensed clubs. Journal of Gambling Studies, 24, 151-174.

Specker, S.M., Carlson, G.A., Edmonson, K.M., Johnson, P.E., \& Marcotte, M. (1996). Psychopathology in pathological gamblers seeking treatment. Journal of Gambling Studies, 12(1), 67-81.

Tavares, H., Martins, S.S., Lobo, D.S.S., Silveira, C.M., Gentil, V., \& Hodgins, D.C. (2003). Factors at play in faster progression for female pathological gamblers: An exploratory analysis. Journal of Clinical Psychiatry, 64, 433-438.

Tavares, H., Zilberman, M.L., Beites, F.J., \& Gentil, V. (2001). Gender differences in gambling progression. Journal of Gambling Studies, 17, 151-159. 
Vander Bilt, J., Dodge, H.H., Pandav, R., Shaffer, H.J., \& Ganguli, M. (2004). Gambling participation and social support among older adults: A longitudinal community study. Journal of Gambling Studies, 20, 373-389.

Volberg, R.A. (2002). The epidemiology of pathological gambling. Psychiatric Annals, 32, 171-178.

Walters, G.D. (2001). Behavior genetic research on gambling and problem gambling: A preliminary meta-analysis of available data. Journal of Gambling Studies, 17, 255-271.

Welte, J.W., Wieczorek, W.F., Barnes, G.M., Tidwell, M.C., \& Hoffman, J.H. (2004). The relationship of ecological and geographic factors to gambling behavior and pathology. Journal of Gambling Studies, 20, 405-423.

Wickwire, E.M., Whelan, J.P., West, R., Meyers, A., McCausland, C., \& Leullen, J. (2007). Perceived availability, risks, and benefits of gambling among college students. Journal of Gambling Studies, 23, 395-408.

Wood, R.T.A., \& Griffiths, M.D. (2007). A qualitative investigation of problem gambling as an escape-based coping strategy. Psychology and Psychotherapy, 80, 107-125.

Xian, H., Scherrer, J.F., Slutske, W.S., Shah, K.R., Volberg, R., \& Eisen, S.A. (2007). Genetic and environmental contributions to pathological gambling symptoms in a 10-year follow-up. Twin Research and Human Genetics, 10, 174-179.

Zaranek, R.R., \& Chapleski, E.E. (2005). Casino gambling among urban elders: Just another social activity? The Journals of Gerontology. Series B, Psychological Sciences and Social Sciences 60(2), S74-S81. 